\title{
Periodontal repair following implantation of beta-tricalcium phosphate with different pore structures in class III furcation defects in dogs
}

\author{
Emiko SAITO ${ }^{1}$, Akira SAITO ${ }^{2}$, Yoshinori KUBOKI ${ }^{3}$, Mariko KIMURA ${ }^{4}$, Yoshiyuki HONMA ${ }^{5}$, Tomomi TAKAHASHI ${ }^{5}$ \\ and Masamitsu KAWANAMI ${ }^{1}$ \\ ${ }^{1}$ Department of Periodontology and Endodontology, Division of Oral Health Science, Hokkaido University Graduate School of Dental Medicine, Kita- \\ 13, Nishi-7, Kita-ku, Sapporo 060-8586, Japan \\ ${ }^{2}$ Department of Oral Rehabilitation, Division of Oral Functional Science, Hokkaido University Graduate School of Dental Medicine, Kita-13, Nishi-7, \\ Kita-ku, Sapporo 060-8586, Japan \\ ${ }^{3}$ Hokkaido University Graduate School of Dental Medicine, Kita-13, Nishi-7, Kita-ku, Sapporo 060-8586, Japan \\ ${ }^{4}$ PILOT Corporation, 1-4-3 Nishiyahata, Hiratsuka 254-8585, Japan \\ ${ }^{5}$ Support Section for Education and Research, Division of Oral Health Science, Hokkaido University Graduate School of Dental Medicine, Kita-13, \\ Nishi-7, Kita-ku, Sapporo 060-8586, Japan \\ Corresponding author, Emiko SAITO; E-mail: water@den.hokudai.ac.jp
}

\begin{abstract}
The aim of this study was to investigate the effect of the pore characteristics of $\beta$-tricalcium phosphate ( $\beta$-TCP) on periodontal healing in class III furcation defects in dogs. Two types of $\beta$-TCP were prepared for grafting; 1 ) a tunnel pipe structure with an inner diameter of $300 \mu \mathrm{m}$, and 2) continuous pore structure with interconnected macropores. The furcations of thirty mandibular premolar teeth were implanted with each type of $\beta$-TCP or were left untreated as control. The dogs were sacrificed 8 weeks post-surgery, and healing was evaluated histologically. Downgrowth of junctional epithelium in the tunnel structure group was significantly less than that in the other two groups $(p<0.01)$. There was significantly more new bone formation and new cementum formation in the tunnel structure group than that in the other two groups $(p<0.01)$. These findings suggested that $\beta$-TCP with a tunnel pipe structure promotes periodontal healing in class III furcation defects.
\end{abstract}

Keywords: Bone grafting, Regeneration, Animal model

\section{INTRODUCTION}

There is an increasing need for periodontal reconstruction in clinical dentistry. Many researchers have shown that the implantation of biomaterials promotes periodontal regeneration in clinical and animal model studies ${ }^{1-5)}$. Biomaterial characteristics, such as porosity, density, and crystallinity, affect the outcome of periodontal regeneration ${ }^{6-11)}$.

Several studies have reported that porous structures enhance bone formation in bone defects ${ }^{12-16)}$. Furthermore, it has been shown that pore size has an effect on vascularization $^{17,18)}$. Pore sizes greater than $140 \mu \mathrm{m}$ induced earlier vessel formation in biomaterials when compared with pore sizes smaller than $140 \mu \mathrm{m}$ or dense particles ${ }^{17)}$. Also, new vessels arising from the residual tissue can increase the number of vessels in macropores, whereas only a few vessels in a macropore could extend into the adjacent macropore through the small connecting area with pore sizes smaller than $140 \mu \mathrm{m}^{18)}$. Vascularization in the defect ensures an adequate supply of nutrients and delivery of cells and growth factors that support the formation of osseous tissue ${ }^{19)}$.

Klenke et al. reported that a porous body with a continuous 100-400 $\mu \mathrm{m}$ pore structure increased new bone formation ${ }^{17)}$. Therefore, we hypothesized that

Color figures can be viewed in the online issue, which is available at J-STAGE.

Received Dec 25, 2011: Accepted Apr 20, 2012

doi:10.4012/dmj.2011-259 JOI JST.JSTAGE/dmj/2011-259 vascularization would enable delivery of cells and supply of nutrients and oxygen to the cells during the initial healing stage without the the small connecting area between macropores.

Beta-tricalcium phosphate ( $\beta$-TCP) belongs to the group of bioactive bioceramics of completely synthetic origin and has been used in periodontology as a bone graft substitute since the $1980 \mathrm{~s}^{1,20-23)}$. At present, there are various types of $\beta$-TCP composed of macropores with small connecting area ${ }^{24-26)}$. We devised a tunnel pipe structure that maintained a continuous pore of $300 \mu \mathrm{m}$. After preparation of cylindrical $\beta$-TCP with randomlyarranged openings as the building block, the $\beta$-TCP was prepared by sintering the samples.

The purpose of this study was to evaluate the effect of the tunnel pipe structure on periodontal regeneration following implantation of $\beta$-TCP in surgically created class III furcation defects in dogs.

\section{MATERIALS AND METHODS}

Animals

The experimental protocol (No. 08-0257) followed the guidelines for the care and use of laboratory animals of the Graduate School of Medicine, Hokkaido University. Thirty mandibular premolar teeth of five beagle dogs (female, 1 year old; mean weight, $9.8 \mathrm{~kg}$ ) were used. The dogs were subjected to plaque control measures 
consisting of twice-weekly brushing and application of $0.5 \%$ chlorhexidine gluconate solution in order to establish healthy gingival conditions prior to surgical procedures.

\section{Preparation and Characterization of $\beta-T C P$}

The $\beta$-TCP slurry was obtained by kneading tricalcium phosphate $\left(\mathrm{Ca}_{3}\left(\mathrm{PO}_{4}\right)_{2}\right)$ with polyvinyl alcohol and distilled water at a molar ratio of 8:2:10. Many hollow cylindrical particles with an inner diameter of 300 $\mu \mathrm{m}$, outer diameter of $500 \mu \mathrm{m}$ and length of $1-2 \mathrm{~mm}$ were prepared by extrusion molding of the slurry. The particles were collected and pressed to release water. The particles of tunnel-pipe $\beta$-TCP were arranged irregularly, forming a cube with sides of $5 \mathrm{~mm}$ (Figs. 1a and $1 b)$. Final $\beta$-TCP in which the tunnel pipe structure was gathered and fixed was sintered at the maximum temperature of 1,100 degree $\mathrm{C}\left({ }^{\circ} \mathrm{C}\right)$ in the presence of oxygen. The porosity of this tunnel-pipe $\beta$-TCP was $72 \%$, which included open porosity and closed porosity calculated as follows: porosity $(\%)=(1$-bulk density of the sample/true density) $\times 100,{ }^{*}$ bulk density of the sample $=\mathrm{W} / \mathrm{V}$, *true density $=3.07 / \mathrm{cm}^{3}(\beta-\mathrm{TCP})$. Data on the images obtained by X-ray powder diffraction (XRD) of tunnel-pipe $\beta$-TCP (Fig. 1e) were provided by the manufacturer. All diffractions peaks were assigned to single-phase $\beta$-TCP and no other phases were observed and the average crystal size was $175 \mathrm{~nm}$. The continuous porous $\beta$-TCP (Osferion ${ }^{\circledR}$, Olympus Terumo Biomaterials Corp., Tokyo, Japan) had a macropore size of 100-400
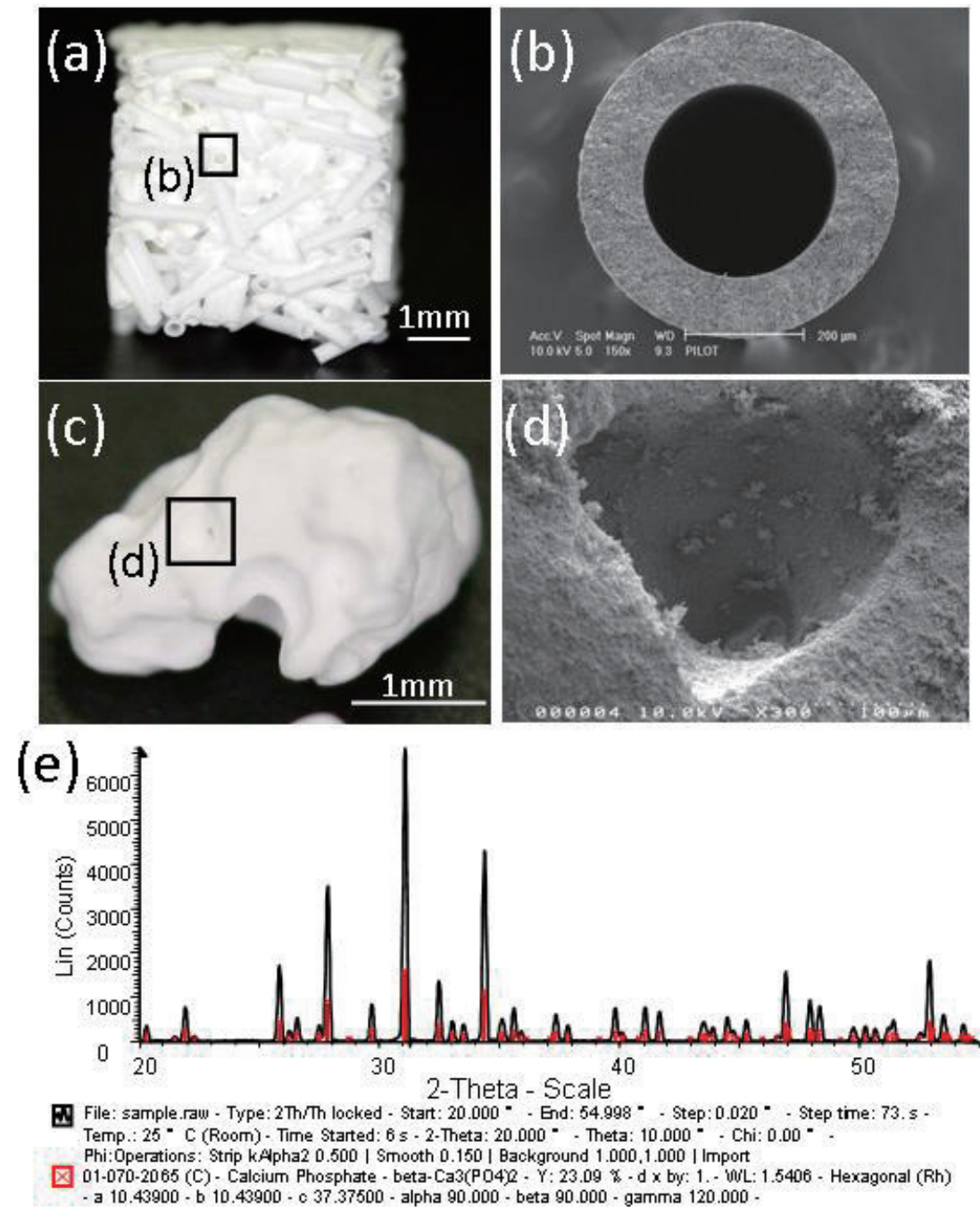

Fig. 1 Macrostructure and microstructure of tunnel-pipe $\beta$-TCP and continuous porous $\beta$-TCP.

(a) A cube with $5 \mathrm{~mm}$ sides was formed by gathering and connecting irregularly arranged particles of tunnel-pipe $\beta$-TCP. (b)The tunnel: inner diameter $300 \mu \mathrm{m}$, outer diameter $500 \mu \mathrm{m}$ and length 1-2 mm. (c) A particle with a diameter of 1,000-2,000 $\mu \mathrm{m}$ and $60 \%$ porosity. (d) A macropore size of 100-400 $\mu \mathrm{m}$ with interconnectivity. (e) The tunnel-pipe $\beta$-TCP was composed of highly crystalline and single-phase $\beta$-TCP, and no other phases were observed. 
$\mu \mathrm{m}$ with interconnectivity, a diameter of 1,000-2,000 $\mu \mathrm{m}$ and $60 \%$ porosity (Figs. 1c and $1 \mathrm{~d}$ ). This was also made of single-phase $\beta$-TCP and the average crystal size was $172 \mathrm{~nm}^{8)}$.

\section{Surgery and implantation}

The surgical procedures were performed under general anesthesia with medetomidine hydrochloride $(5 \mu \mathrm{g} / \mathrm{kg}$, Domitor $^{\circledR}$, Meiji Seika, Tokyo, Japan) and ketamine hydrochloride $\left(2.9 \mathrm{mg} / \mathrm{kg}\right.$, Ketaral $50^{\circledR}$, Sankyo, Tokyo, Japan) and local anesthesia with lidocaine hydrochloride (2\% with 1:80,000 epinephrine, Xylocaine ${ }^{\circledR}$, DENTSPLY SANKIN, Tokyo, Japan). After reflection of a mucoperiosteal flap, the interradicular bone of all second, third and fourth premolars was completely removed with rotating burs under irrigation and hand micro Ochsebein chisels to create through-and-through furcation defects. The defect height from the cementoenamel junction (CEJ) to the reduced alveolar crest was $4 \mathrm{~mm}$. The exposed root surfaces were planed with curettes in order to remove the periodontal ligament and cementum. At this point, the teeth were randomly assigned to one of three treatment groups based on a random computer-generated list.

In the T group $(n=10), \beta$-TCP was shaped using a diamond bur to fit the furcation space. Then, $\beta$-TCP was implanted into the furcation and the remaining space was filled with the $\beta$-TCP pipe particles. In the CP group $(n=10)$, the furcation defect was filled with continuous porous $\beta$-TCP. The furcation was not treated in the remaining ten teeth, which served as control.

After implantation, the flaps were positioned with the gingival margins of the flaps at the CEJ and sutured.

\section{Wound management}

Sutures were removed 10 days after the surgical procedure. Plaque control measures included weekly brushing and application of $0.5 \%$ chlorhexidine gluconate solution throughout the healing period.

\section{Histological processing and histometric analysis}

The dogs were sacrificed 8 weeks after the surgical procedure. Tissue blocks including teeth, bone and soft tissues were resected. Blocks were fixed in $10 \%$ buffered formalin, decalcified in 10\% ethylenediamine tetraacetic acid (EDTA, Wako, Tokyo, Japan) solution, trimmed, dehydrated, and embedded in paraffin. Serial sections, $4 \mu \mathrm{m}$ thick, were prepared in the mesio-distal plane. Sections of the middle portion at bucco-lingual width of the crown were stained with hematoxylin and eosin and tartrate-resistant acid phosphatase (TRAP) stain.

Measurements of each specimen were carefully performed by one examiner (YH), who was blinded to the study protocol. The following measurements were performed using Scion Image ${ }^{\circledR}$ (National Institute of Health) (Fig. 2). For determination of the defect size, the area from the mesial and distal end points of root planing to the fornix was regarded as the bone defect area (BDA). The tissues formed from the apical border in a coronal direction after each treatment were regarded as newly formed tissue. The following parameters were also determined: 1) the percentage of regenerated bone area, calculated by the regenerated bone area/BDA $\times 100$; 2 ) the percentage of space composed of new bone and $\beta$-TCP, calculated by the regenerated bone area and remaining $\beta$-TCP area/BDA $\times 100 ; 3)$ the percentage of epithelium, calculated by the linear extension of root surface covered by epithelial tissue/length of the root planed surface from the mesial end to the distal end $(\mathrm{RL}) \times 100$; and 4 ) the percentage of new cementum length, calculated by the total length of regenerated cementum or cementum-like deposit on the root/RL×100. The number of blood vessels inside the pore that was
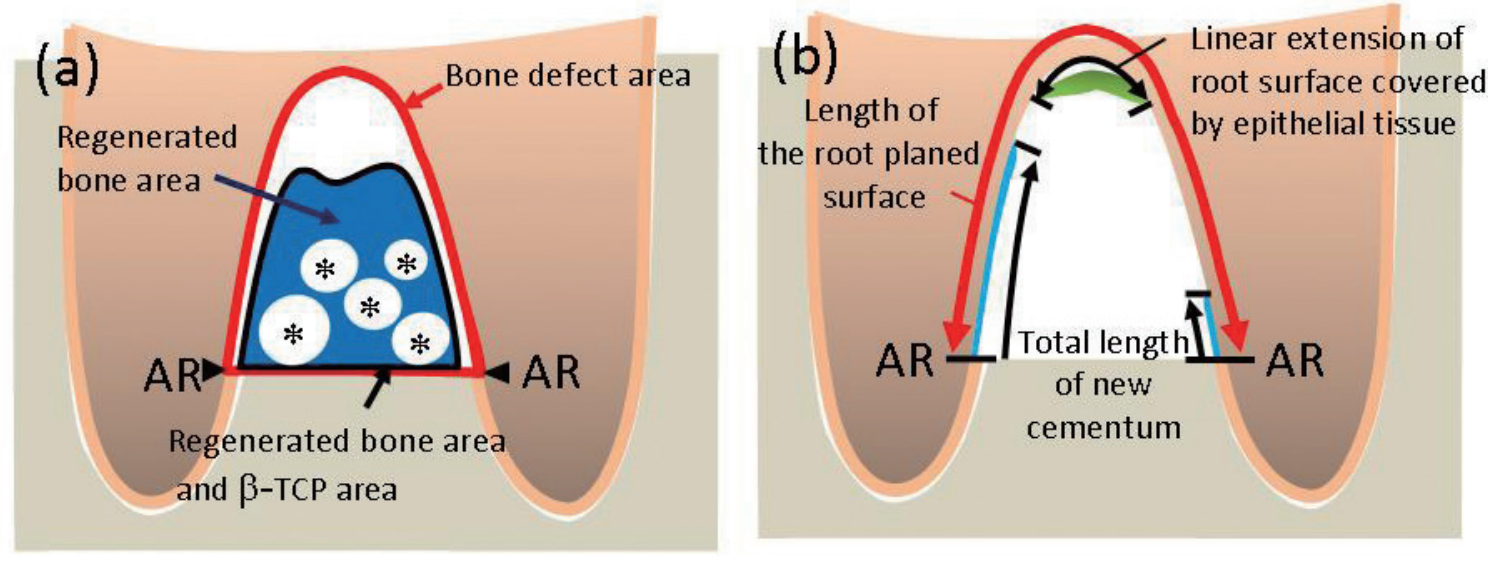

Fig. 2 Schematic illustration of landmarks used for histometric measurements. (a) Schematic illustration of the regenerated bone and/or $\beta$-TCP. (b) Schematic illustration of the regenerated new cementum and epithelial tissue. $\mathrm{AR}=$ apical end of the root planed surface; Black asterisk=remaining $\beta$-TCP. 


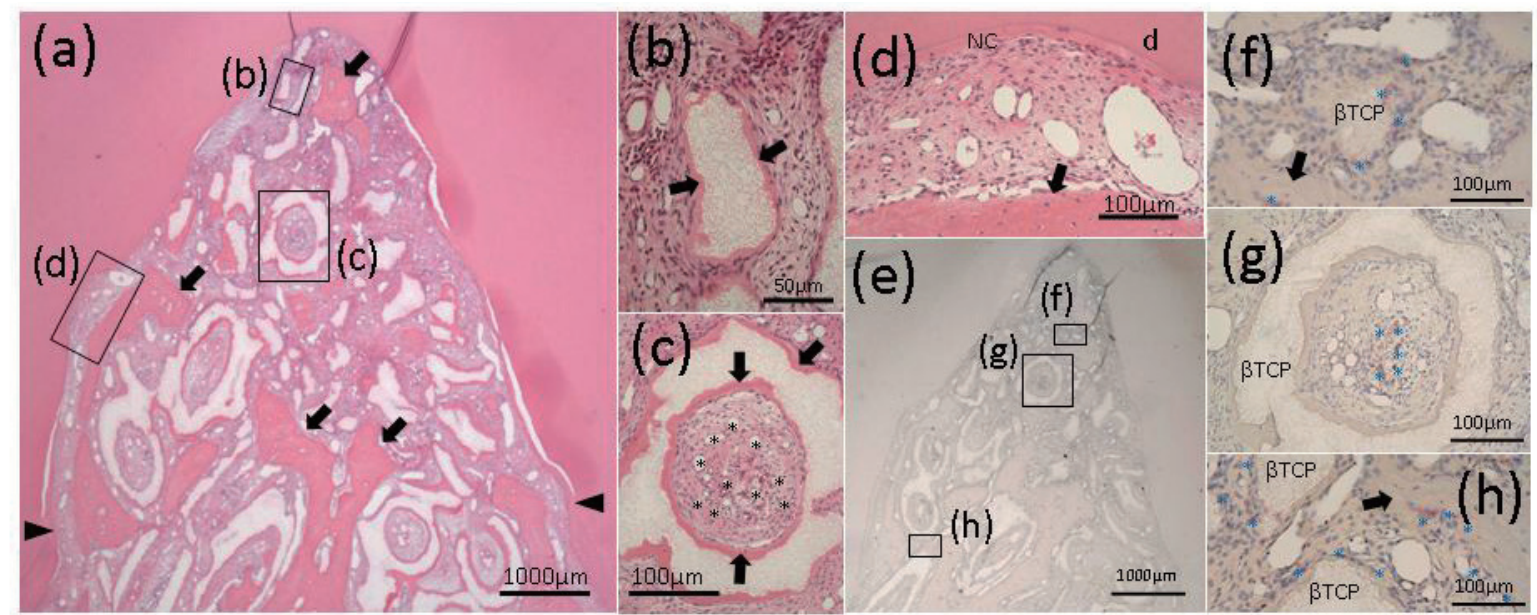

Fig. 3 A representative case from the T group.

(a) Overview: Note the extensive new bone (black arrow) formation. (b) New bone had formed on the outer surfaces of $\beta$-TCP near the fornix of the furcation. (c) Several blood vessels (black asterisks) had formed in the center of the pipe tunnel. (d) New connective tissue fibers were oriented parallel or inclined to the root surface and embedded in both new cementum (NC) and new bone. (e) through (h) Numerous multinucleated cells (blue asterisks) were seen throughout the entire furcation. ((a) through (d)) Hematoxylin and eosin. ((e) through (h)) Tartrate-resistant acid phosphatase. Filled arrowhead=the apical end of root-planed surface; $d=$ root dentin.

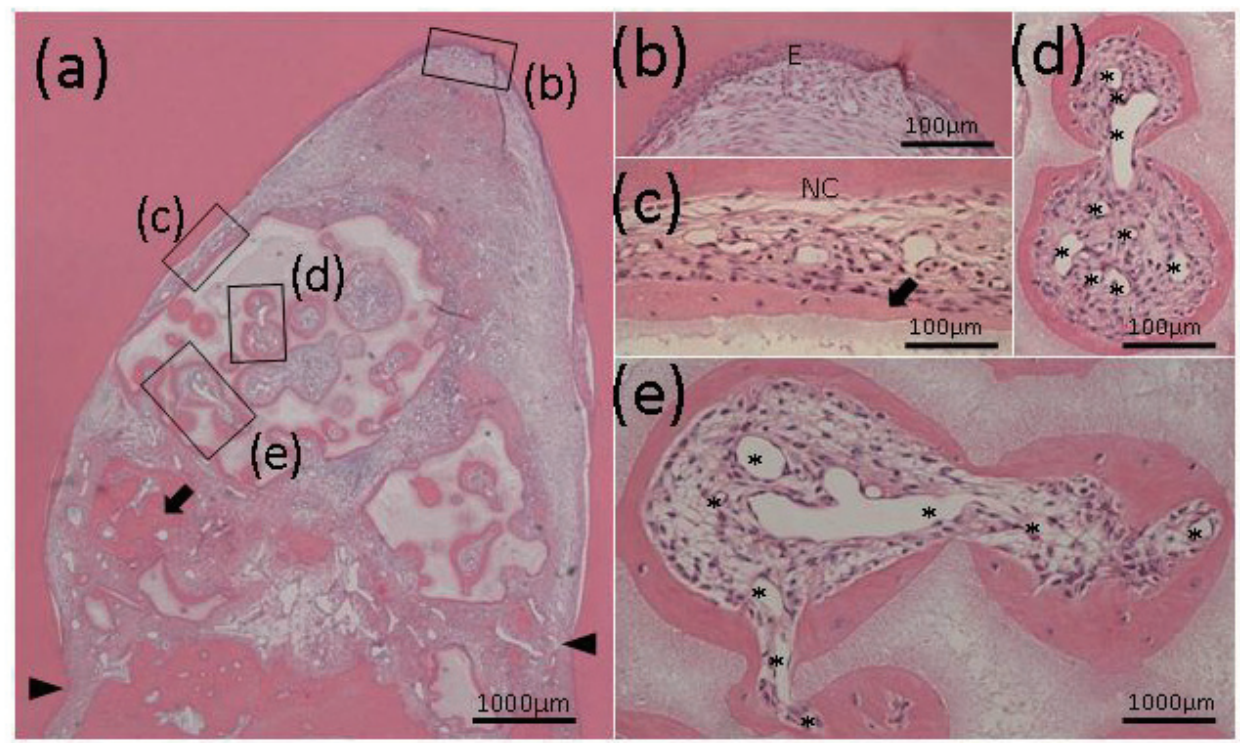

Fig. 4 A representative case from the CP group.

(a) through (e) Continuous porous $\beta$-TCP group: New bone (black arrow) was observed near the residual bone surrounding the $\beta$-TCP. (b) Gingival epithelium (E) was observed in the fornix of the furcation. (c) New connective tissue fibers were oriented parallel to the root surface and embedded in both new cementum and new bone on $\beta$-TCP. (d) and (e) The new bone was observed on the inner surfaces of $\beta$-TCP. In the macropore of $\beta$-TCP, several blood vessels were observed. In contrast, one or few vessels were observed in the area connecting macropores (black asterisks). ((a) through (e)) Hematoxylin and eosin. Filled arrowhead=the apical end of root-planed surface. 
shaped like a closed circle or ellipse was determined in the $\mathrm{T}$ group and $\mathrm{CP}$ group. In the $\mathrm{T}$ group, the number of inner blood vessels was determined with respect to each pore of each sample and the mean of each sample was calculated. In the CP group, the numerical value of the minor axis of measurement object was measured. A pore with a diameter more than or equal to $100 \mu \mathrm{m}$ was defined as a large pore and the pore with a diameter less than or equal to $20 \mu \mathrm{m}$ was defined as small pore. The mean numbers of blood vessels, large pores and small pores for each sample were calculated.

\section{Data analysis}

The mean \pm SD of each measurement was calculated for each tooth from selected sections. Statistical differences were analyzed using the Kruskal-Wallis test. The number of blood vessels was analyzed using the Mann-Whitney $\mathrm{U}$ test. All statistical procedures were performed using SPSS 10.0 J (S.P.S.S. Co. Ltd., Tokyo, Japan)

\section{RESULTS}

\section{Clinical observations}

Clinical healing after the surgical procedures was uneventful with minimum indications of inflammation throughout the experimental period.

\section{Histological observations}

In the $\mathrm{T}$ group, long junctional epithelium was not observed in the furcation of 7/10 specimens. New bone

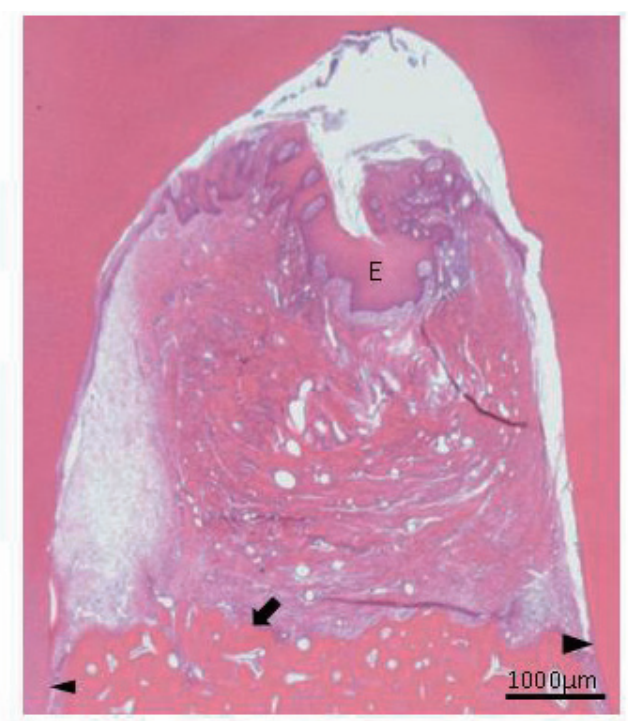

Fig. 5 A representative case from $\mathrm{C}$ group. Gingival epithelium was observed in the fornix of the furcation (E). Limited new bone had formed at the bottom of the furcation defect near the residual bone. Hematoxylin and eosin. Filled arrowhead=the apical end of root-planed surface. was observed up to the fornix of the furcation (Figs. 3a and b). Several blood vessels had formed in the center of each pipe tunnel directed horizontally (Fig. 3c). Numerous multinucleated cells adhered to the $\beta$-TCP surface and there was new bone throughout the entire furcation (Figs. $3 \mathrm{e}^{-} \mathrm{h}$ ). New connective tissue fibers oriented parallel or inclined to the root surface and embedded in both new cementum and new bone were observed (Fig. 3d).

In the CP group, long junctional epithelium was observed in the furcation of all specimens (Figs. 4a and b). New bone was observed on the inner and outer surfaces of $\beta$-TCP. In the macropore of $\beta$-TCP, several blood vessels were observed. In contrast, one or few vessels were observed in the small connecting area between macropores (Figs. $4 \mathrm{~d}$ and e). New cementum with inserting collagen fibers had formed on the rootplaned surface (Fig. 4c).

In the C group (Fig. 5), gingival epithelium was observed in the furcation of all specimens and inflammatory cells appeared in the connective tissue under the epithelium. Limited new bone was observed near the residual bone of the furcation defects. Limited amounts of new cementum with inserting collagen fibers were observed on the root-planed surface.

\section{Histometric analysis}

There were no significant differences in bone defect area among the three groups. The epithelium was significantly less in the $\mathrm{T}$ group than in the $\mathrm{C}$ and $\mathrm{CP}$ groups $(p<0.01)$ (Table 1$)$. The regenerated bone area and space composed of regenerated bone and $\beta$-TCP were significantly greater in the Troup than in the $\mathrm{C}$ and $\mathrm{CP}$ groups $(p<0.01)$ (Table 1). There was $69.4 \pm 6.1 \%$ newly formed cementum in the T group, significantly greater than in the $\mathrm{CP}$ and $\mathrm{C}$ groups $(p<0.01)$ (Table 1$)$. The mean number of inner blood vessels was $16.5 \pm 1.8$ in the $\mathrm{T}$ group and $5.2 \pm 0.9$ in the $\mathrm{CP}$ group. In the CP group, the large pore area was $9.0 \pm 0.9$ and small pore area was $1.2 \pm 0.2$. The number of blood vessels was significantly greater in the $\mathrm{T}$ group than in the $\mathrm{CP}$ group (Table 2).

\section{DISCUSSION}

Previous studies have reported varied outcomes of periodontal regeneration therapy in furcation defect $\mathrm{s}^{27-29)}$. It was speculated that periodontal regeneration might be affected by local factors, such as the width and height of furcation defects and the size of the entrance of the furcation. As the characteristics of the first cells to populate a wound dictate the nature and quality of tissue that forms there, it is important that cells from the periodontal ligament and alveolar bone are allowed to initially recolonize periodontal wounds, rather than cells from soft fibrous connective tissue and gingival epithelium $^{30}$.

The regenerated bone area in the $\mathrm{T}$ group was significantly larger than in the $\mathrm{C}$ and $\mathrm{CP}$ groups in this study. This could be attributed to a difference in the characteristics of the implant materials. The phase 
Table 1 Histometric analysis of periodontal healing(Group mean \pm SD in percentage)

\begin{tabular}{lccc}
\multicolumn{1}{c}{ Parameter } & $\begin{array}{c}\text { T group } \\
(n=10)\end{array}$ & $\begin{array}{c}\text { CP group } \\
(n=10)\end{array}$ & $\begin{array}{c}\text { C group } \\
(n=10)\end{array}$ \\
\hline $\begin{array}{l}\text { Regenerated bone area } \\
\text { Space composed of regenerated } \\
\text { bone and } \beta \text {-TCP }\end{array}$ & $38.6 \pm 4.3^{* \dagger}$ & $30.8 \pm 3.4$ & $24.2 \pm 9.3$ \\
Epithelium & $72.8 \pm 1.3^{* \dagger}$ & $57.6 \pm 9.3^{\ddagger}$ & $24.2 \pm 9.3$ \\
New cementum & $6.94 \pm 5.6^{* \dagger}$ & $29.5 \pm 8.8$ & $48.2 \pm 3.1$ \\
\hline
\end{tabular}

$n=$ number of sites; $P$ value by Kruskal-Wallis test.

* Significantly different from CP group $(p<0.01)$.

$\dagger$ Significantly different from C group $(p<0.01)$.

$\star$ Significantly different from C group $(p<0.05)$.

Table 2 Number of vessels in $\beta$-TCP $($ Group mean \pm SD)

\begin{tabular}{ccc}
\hline Parameter & $\begin{array}{c}\text { T group } \\
(n=10)\end{array}$ & $\begin{array}{c}\text { CP group } \\
(n=10)\end{array}$ \\
\hline Number of vessels & $16.5 \pm 1.8$ & $5.2 \pm 0.9^{*}$ \\
\cline { 2 - 3 } & & $\begin{array}{c}\text { large pore area } \\
\text { small pore area } \\
1.0 \pm 0.9^{* \dagger}\end{array}$ \\
\hline
\end{tabular}

$n=$ number of sites; $P$ value by Mann-Whitney U test.

* Significantly different from T group $(p<0.01)$.

$\dagger$ Significantly different from Micro pore of CP group $(p<0.01)$.

purity of the two types of $\beta$-TCP used in this study was $100 \%$ beta phase and the crystal size was similar. However, the porosity of the tunnel-pipe $\beta$-TCP (72\%) was greater than that of continuous porous $\beta$-TCP $(60 \%)$. These results confirmed the findings of previous reports which demonstrated that high porosity promoted greater bone formation ${ }^{31-32)}$. The volume of implanted $\beta$-TCP remaining within the furcation in the $\mathrm{T}$ group was less than that in the CP group, which could explain the difference in the porosity of the implanted material. The amount of $\beta$-TCP degradation in the T group was significantly less than that in the $\mathrm{CP}$ group. Although higher porosity has been shown to promote resorption of $\beta$-TCP and replacement with bone tissue, the results of the present study did not support these findings. Resorption is affected by cellular phagocytosis and surrounding $\mathrm{pH}$; however, $\beta$-TCP degradation would have been inhibited because the surface of $\beta$-TCP was covered with new bone. When osteoconduction is greater, new bone would cover the surface of $\beta$-TCP. Osteoconduction is dependent on not only the porosity but also the pore diameter. In this study, there were significantly more blood vessels in the pore of the $\beta$-TCP in the $\mathrm{T}$ group than that in the $\mathrm{CP}$ group. The tunnel structure might have served as an efficient conductor for vessel invasion. According to Rodriguez et al., vascularization is crucial for the development and repair of most tissues, and is a prerequisite for the healing of bone defects ${ }^{33)}$. Vascularization of the implantation site ensures adequate supply of nutrients, prompt removal of metabolic by-products, and delivery of cells and growth factors that support the formation of osseous tissue. In the $\mathrm{T}$ group, a number of vessels could be observed in the center of the tunnel structures, whereas, in the CP group, several vessels were observed in the macropore structures with only one or a few vessels in the small connecting area between macropores. The small number of vessels in the small connecting area would limit the supply of cells to the fornix of the furcation in the $\mathrm{CP}$ group. On the other hand, the presence of vessels in the tunnel structure might have supplied cells and supported the formation of osseous tissue towards the fornix of the furcation.

Regarding the downgrowth of gingival epithelium, several studies have reported that the implantation of dense $\beta$-TCP in surgically created intrabony and furcation defects may result in the formation of a long epithelial attachment similar to that in a non-implant group ${ }^{34-38)}$. It is suggested that $\beta$-TCP might have little effect on the recolonization of the gingival epithelium. However, in this study, downgrowth of gingival epithelium in the $\mathrm{T}$ group and $\mathrm{CP}$ group was significantly smaller than 
in the $\mathrm{C}$ group. In addition, downgrowth of gingival epithelium in the $\mathrm{T}$ group was significantly smaller than in the CP group. Vascularization of the implantation site in the early healing stage might affect the downgrowth of epithelium in the furcation defects by promoting the formation of connective tissue containing bone, periodontal ligament and gingival connective tissue. The connective tissue formation would inhibit downgrowth of the gingival epithelium in the furcation defects. From this point of view, the tunnel structure would decrease the downgrowth of gingival epithelium in comparison to the $\mathrm{CP}$ group.

New cementum formation in the $\mathrm{T}$ group was greater than in the $\mathrm{CP}$ and $\mathrm{C}$ groups. In the $\mathrm{T}$ group, new cementum was observed as deposition on the resorption lacunae in part of the root dentin. Because odontoclasts have expression patterns of cathepsin $\mathrm{K}$ and matrix metalloproteinase-9 (MMP-9) similar to osteoclasts, the odontoclasts could have been stimulated by the active bone formation and high bone turnover ${ }^{39}$. Götz et al. reported that cementoblasts were involved in the resorption-repair sequence, which is considered to be a coupling process as in bone ${ }^{40)}$. Similarly, preparation for new cementum formation might start adjacent to resorption areas. Multinucleated cells adhered to not only the $\beta$-TCP surface but also new bone throughout the entire furcation. Consequently, the tunnel structure of $\beta$-TCP would also induce new cementum formation.

\section{CONCLUSION}

The present findings demonstrate that the tunnel structure of $\beta$-TCP induced an increase in cells and blood vessels derived from the residual bone, which enhanced periodontal regeneration in class III furcation defects.

\section{ACKNOWLEDGMENTS}

This study was supported by Grants-in-Aid for Encouragement of Young Scientists (22792078 to Dr. E. Saito) and Scientific Research (22592307 to Dr. A. Saito) from the Ministry of Education, Science, Sports and Culture of Japan. The authors report no conflicts of interest related to this study.

\section{REFERENCES}

1) Wada $T$, Wu CH, Sugita H, Sugita N, Katagiri S, Shimizu M, Hara K. Autogenous, allogenic, and beta-TCP grafts: comparative effectiveness in experimental bone furcation defects in dogs. J Oral Implantol 1989; 15: 231-236.

2) Stein JM, Fickl S, Yekta SS, Hoischen U, Ocklenburg C, Smeets R. Clinical evaluation of a biphasic calcium composite grafting material in the treatment of human periodontal intrabony defects: a 12 -month randomized controlled clinical trial. J Periodontol 2009; 80: 1774-1782.

3) Tsao YP, Neiva R, Al-Shammari K, Oh TJ, Wang HL. Effects of a mineralized human cancellous bone allograft in regeneration of mandibular Class II furcation defects. J Periodontol 2006; 77: 416-425.

4) Tal H, Pitaru S, Moses O, Kozlovsky A. Collagen gel and membrane in guided tissue regeneration in periodontal fenestration defects in dogs. J Clin Periodontol 1996; 23: 1-6.

5) Reynolds MA, Aichelmann-Reidy ME, Branch-Mays GL, Gunsolley JC. The efficacy of bone replacement grafts in the treatment of periodontal osseous defects. A systematic review. Ann Periodontol 2003; 8: 227-265.

6) Schmitt JM, Buck DC, Joh SP, Lynch SE, Hollinger JO. Comparison of porous bone mineral and biologically active glass in critical-sized defects. J Periodontol 1997; 68: 10431053.

7) Nery EB, LeGeros RZ, Lynch KL, Lee K. Tissue response to biphasic calcium phosphate ceramic with different ratios of HA/beta TCP in periodontal osseous defects. J Periodontol 1992; 63: 729-735.

8) IrokawaD, OtaM, YamamotoS, Shibukawa Y, YamadaS. Effect of $\beta$ tricalcium phosphate particle size on recombinant human platelet-derived growth factor-BB-induced regeneration of periodontal tissue in dog. Dent Mater J 2010; 29: 721-730.

9) Shapoff CA, Bowers GM, Levy B, Mellonig JT, Yukna RA. The effect of particle size on the osteogenic activity of composite grafts of allogeneic freeze-dried bone and autogenous marrow. J Periodontol 1980; 51: 625-630.

10) Zaner DJ, Yukna RA. Particle size of periodontal bone grafting materials. J Periodontol 1984; 55: 406-409.

11) Yukna RA. Synthetic bone grafts in periodontics. Periodontol 2000 1993; 1: 92-99.

12) Kuboki Y, Jin QM, Takita H. Geometry of carriers controlling phenotypic expression in BMP-induced osteogenesis and chondrogenesis. J Bone Joint Surg Am 2001; 83: 105-115.

13) Jin QM, Takita H, Kohgo T, Atsumi K, Itoh H, Kuboki Y. Effects of geometry of hydroxyapatite as a cell substratum in BMP-induced ectopic bone formation. J Biomed Mater Res 2000; 52: 491-499.

14) Tsuruga E, Takita H, Itoh H, Wakisaka Y, Kuboki Y. Pore size of porous hydroxyapatite as the cell-substratum controls BMP-induced osteogenesis. J Biochem 1997; 121: 317-324.

15) Kuboki Y, Saito T, Murata M, Takita H, Mizuno M, Inoue M, Nagai N, Poole AR. Two distinctive BMP-carriers induce zonal chondrogenesis and membranous ossification, respectively; geometrical factors of matrices for cell-differentiation. Connect Tissue Res 1995; 32: 219-226.

16) Kuboki $Y$, Takita H, Kobayashi D, Tsuruga E, Inoue M, Murata M, Nagai N, Dohi Y, Ohgushi H. BMP-induced osteogenesis on the surface of hydroxyapatite with geometrically feasible and nonfeasible structures: topology of osteogenesis. J Biomed Mater Res 1998; 39: 190-199.

17) Klenke FM, Liu Y, Yuan H, Hunziker EB, Siebenrock KA, Hofstetter W. Impact of pore size on the vascularization and osseointegration of ceramic bone substitutes in vivo. J Biomed Mater Res A 2008; 85: 777-786.

18) Artel A, Mehdizadeh H, Chiu YC, Brey EM, Cinar A. An agent-based model for the investigation of neovascularization within porous scaffolds. Tissue Eng Part A 2011; 17: 21332141.

19) Laschke MW, Harder Y, Amon M, Martin I, Farhadi J, Ring A, Torio-Padron N, Schramm R, Rücker M, Junker D, Häufel JM, Carvalho C, Heberer M, Germann G, Vollmar B, Menger $\mathrm{MD}$. Angiogenesis in tissue engineering: breathing life into constructed tissue substitutes. Tissue Eng 2006; 12: 20932104.

20) Zerbo IR, Bronckers AL, de Lange G, Burger EH. Localisation of osteogenic and osteoclastic cells in porous beta-tricalcium phosphate particles used for human maxillary sinus floor elevation. Biomaterials 2005; 26: 1445-1451.

21) Ogose A, Kondo N, Umezu H, Hotta T, Kawashima H, Tokunaga K, Ito T, Kudo N, Hoshino M, Gu W, Endo N. Histological assessment in grafts of highly purified betatricalcium phosphate (OSferion) in human bones. Biomaterials 2006; 27: 1542-1549.

22) Knabe C, Koch C, Rack A, Stiller M. Effect of beta-tricalcium 
phosphate particles with varying porosity on osteogenesis after sinus floor augmentation in humans. Biomaterials 2008; 29: 2249-2258.

23) Martinez A, Franco J, Saiz E, Guitian F. Maxillary sinus floor augmentation on humans: Packing simulations and 8 months histomorphometric comparative study of anorganic bone matrix and $\beta$-tricalcium phosphate particles as grafting materials. Mater Sci Eng C Mater Biol Appl 2010; 30: 763769.

24) Karageorgiou V, Kaplan D. Porosity of 3D biomaterial scaffolds and osteogenesis. Biomaterials 2005; 26: 54745491.

25) Bai F, Wang Z, Lu J, Liu J, Chen G, Lv R, Wang J, Lin K, Zhang J, Huang X. The correlation between the internal structure and vascularization of controllable porous bioceramic materials in vivo: a quantitative study. Tissue Eng Part A 2010; 16: 3791-3803.

26) Schumacher M, Deisinger U, Detsch R, Ziegler G. Indirect rapid prototyping of biphasic calcium phosphate scaffolds as bone substitutes: influence of phase composition, macroporosity and pore geometry on mechanical properties. J Mater Sci Mater Med 2010; 21: 3119-3127.

27) Palioto DB, Joly JC, de Lima AF, Mota LF, Caffesse R. Clinical and radiographic treatment evaluation of class III furcation defects using GTR with and without inorganic bone matrix. J Clin Periodontol 2003; 30: 1-8.

28) Donos N, Glavind L, Karring T, Sculean A. Clinical evaluation of an enamel matrix derivative and a bioresorbable membrane in the treatment of degree III mandibular furcation involvement: a series of nine patients. Int $\mathrm{J}$ Periodontics Restorative Dent 2004; 24: 362-369.

29) Mellonig JT, Valderrama Mdel P, Cochran DL. Histological and clinical evaluation of recombinant human platelet-derived growth factor combined with beta tricalcium phosphate for the treatment of human Class III furcation defects. Int J Periodontics Restorative Dent 2009; 29: 169-177.

30) Melcher AH. On the repair potential of periodontal tissues. J Periodontol 1976; 47: 256-260.

31) Lu J, Descamps M, Dejou J, Koubi G, Hardouin P, Lemaitre J, Proust J. The biodegradation mechanism of calcium phosphate biomaterials in bone. J Biomed Mater Res 2002; 63: 408-412.
32) Lin K, Yuan W, Wang L, Lu J, Chen L, Wang Z, Chang J. Evaluation of host inflammatory responses of $\beta$-tricalcium phosphate bioceramics caused by calcium pyrophosphate impurity using a subcutaneous model. J Biomed Mater Res B Appl Biomater 2011; 99: 350-358.

33) Rodriguez AP, Missana L, Nagatsuka H, Gunduz M, Tsujigiwa H, Rivera R, Nagai N. Efficacy of atelocollagen honeycomb scaffold in bone formation using KUSA/A1 cells. J Biomed Mater Res A 2006; 77: 707-717.

34) Lee JS, Wikesjö UM, Jung UW, Choi SH, Pippig S, Siedler M, Kim CK. Periodontal wound healing/regeneration following implantation of recombinant human growth/differentiation factor-5 in a b-tricalcium phosphate carrier into one-wall intrabony defects in dogs. J Clin Periodontol 2010; 37: 382389.

35) Barney VC, Levin MP, Adams DF. Bioceramic implants in surgical periodontal defects. A comparison study. J Periodontol 1986; 57: 764-770.

36) Al-Ali W, Bissada NF, Greenwell H. The effect of local doxycycline with and without tricalcium phosphate on the regenerative healing potential of periodontal osseous defects in dogs. J Periodontol 1989; 60: 582-590.

37) Stavropoulos A, Windisch P, Szendröi-Kiss D, Peter R, Gera I, Sculean A. Clinical and histologic evaluation of granular Betatricalcium phosphate for the treatment of human intrabony periodontal defects: a report on five cases. J Periodontol 2010; 81: 325-334.

38) Stavropoulos A, Windisch P, Gera I, Capsius B, Sculean A, Wikesjö UME. A phase IIa randomized controlled clinical and histological pilot study evaluating rhGDF-5/ $\beta$-TCP for periodontal regeneration. J Clin Periodontol 2011; 38: 10441054.

39) Tsuchiya M, Akiba Y, Takahashi I, Sasano Y, Kashiwazaki J, Tsuchiya S, Watanabe M. Comparison of expression patterns of cathepsin K and MMP-9 in odontoclasts and osteoclasts in physiological root resorption in the rat molar. Arch Histol Cytol 2008; 71: 89-100.

40) Götz W, Kunert D, Zhang D, Kawarizadeh A, Lossdörfer S, Jäger A. Insulin-like growth factor system components in the periodontium during tooth root resorption and early repair processes in the rat. Eur J Oral Sci 2006; 114: 318-327. 